\title{
Systematic analysis of future competences affected by Industry 4.0
}

\author{
András Gábor ${ }^{1}$ Ildikó Szabó $^{2}$ Fizar Ahmed ${ }^{2}$ \\ ${ }^{1}$ Future Internet Living Lab Association, Közraktár u. 12/A, 1093 Budapest, Hungary \\ agaborefilab.hu \\ ${ }^{2}$ Corvinus University of Budapest, Fővám tér 13-15., 1093 Budapest, Hungary \\ ildiko.szabo2@uni-corvinus.hu \\ fizarbdeyahoo.com
}

\begin{abstract}
Digital transformations boosted by new technological innovations entail restructured industrial processes and requalified skilled workers. Educational institutions must provide qualifications with learning outcomes fitting to these requirements. Nowadays skill gap analysis between both sides of labor market is a crucial research topic, but researchers mostly draw consequences from experts' visions, trends in past data and not from systematic analysis. Educational institutions must gather information about competences required in the future to start transferring them these relevant knowledge in time. This paper presents an information system dedicated to estimate the importance of actual competences in the future based on different business scenarios.
\end{abstract}

Keywords: Industry 4.0, future competence, skill gap analysis, I/O model.

\section{Introduction}

Researchers emphasize different aspects of Industry 4.0. Lu [17] summarized it as "an integrated, adapted, optimized, service-oriented, and interoperable manufacturing process which is correlate with algorithms, big data, and high technologies". Nevertheless, it has social aspects as well, because it takes effect on the demand side of labor market due to the emerging technologies (e.g. Smart Systems, Blockchain, Virtual Reality, Internet of Things etc.) applied by organizations to improve the effectiveness of their business processes. Supply chain processes including human aspects are transforming. The communication between human and machine is getting more interactive, presenting two-way interaction due to the machine learning developments. Technological competences required to execute procurement, production or sales activities are continually changing due to the short technological lifecycles. Adaptive, innovative, responsible decision makers desiring for knowledge are ideal employees in this variant environment. Educational institutions must rethink how the students' attitudes, knowledge, skills, autonomy, responsibility, meaning competences have to be improved during their studies. 
New pedagogical approaches, new teaching methods are not so efficient if the labor market needs different training scope than an educational institute can provide. Future needs have to be predicated not just detected, because the approval or accreditation processes are long-term process in the world of education.

From a long-term research point of view, it is more interesting the future demand compliance with supply, because this approach fits better to regional development, managing links between academia and economy. Several directives, surveys, studies try to envisage the future skill demand, just to mention a recent EU wide initiative: S3 strategy [1]. In addition, demography can be mentioned - the growing silver economy, the economic growth, investments create new jobs, and the development of technology, a.o. ICT. According to a popular and scientifically less grounded topos many foresees the AI 'hostile' takeover of labor market. (There is life after AI winter.)

One possible solution is to model the economy and try to conclude the future workforce demand. Doing this via well-known and approved input-output analysis model and using standardized statistical data, mainly from open sources (CSO, Eurostat open data), the model mirrors with good accuracy the economy sector-wise. The overall output (GDP), and labor intensity are important results for the next phase of modelling. Labor usage is presented in occupational distribution. In the next step, there are three main tasks to be performed: (1) translate the occupational structure into competence structure, (2) using the model create several future scenario in order to generate the future demand; (3) match the demand with the supply.

The overall purpose of modelling and analysis is to conclude what skills (competences) will be required by the world of labor on the selected time horizon, in region, sector, in selected job roles and/or occupations. After having learnt the requested skills (competences), the supply can be compared with the demand. In our investigation, we narrowed the supply to the fresh graduates. In reality, the supply is bigger if we take into account the number of potential workforce having in mind career exchange, reintegrated unemployed people and the mobility. On one hand, this the bias of the analysis results, on other hand it is very difficult to get realistic and exact figures related to the mentioned subgroups. In order to conduct the analysis several steps need to be performed.

This paper presents a system met these above-mentioned requirements. Section 1 deals with other research approaches to predict future competences and their relation with our solution. Having clarified the related main concepts in Section 2-5, a systematic analysis performed with this system is presented in Section 6. Conclusions about limitations and future work are drawn in Section 7.

\subsection{State of the Art}

Different studies deal with forecasting future competences. Systematic analysis is our main goal, so Approaches using models or other methods for synthetizing knowledge sources fall into our scope. Hence two research groups and two international institutions (OECD and CEDEFOP) specialized on this topic were selected to present their approaches. Their main characteristics are collected in the following table.

- Authors identify the research approach unequivocally. 
- Scope presents that this a general forecast or focuses on a specialized area.

- Input shows which sources were used to build a model or determining predictions.

- Method is the key element of a research, because it reflects the reality in a restricted manner.

- Flexibility means that this research is capable of evaluating the small changes of factors.

\begin{tabular}{|c|c|c|c|c|}
\hline Authors & Scope & Inputs & Methods & Flexibility \\
\hline $\begin{array}{l}\text { Hartmann and } \\
\text { Bovenschulte } \\
\text { [2] }\end{array}$ & $\begin{array}{l}\text { Skill needs } \\
\text { prognosis spe- } \\
\text { cifically on In- } \\
\text { dustry } 4.0\end{array}$ & $\begin{array}{l}\text { Experts' opin- } \\
\text { ions }\end{array}$ & $\begin{array}{l}\text { Virtual Tech- } \\
\text { nology } \\
\text { Roadmap, Or- } \\
\text { ganizational } \\
\text { scenarios, } \\
\text { Quantitative } \\
\text { and qualita- } \\
\text { tive skill } \\
\text { needs analysis }\end{array}$ & $\begin{array}{l}\text { Roadmap has } \\
\text { to be renewed }\end{array}$ \\
\hline $\begin{array}{l}\text { Institute for } \\
\text { the Future for } \\
\text { the University } \\
\text { of Phoenix } \\
\text { Research In- } \\
\text { stitute [3] }\end{array}$ & $\begin{array}{l}\text { Six key driv- } \\
\text { ers and ten } \\
\text { most relevant } \\
\text { skill areas }\end{array}$ & $\begin{array}{l}\text { Experts's } \\
\text { foresights col- } \\
\text { lected during a } \\
\text { workshop }\end{array}$ & $\begin{array}{l}\text { IFTF's signals } \\
\text { methodology }\end{array}$ & $\begin{array}{l}\text { No. There are } \\
\text { not quantita- } \\
\text { tive correla- } \\
\text { tions between } \\
\text { the factors }\end{array}$ \\
\hline $\begin{array}{l}\text { OECD report } \\
\text { [4] }\end{array}$ & $\begin{array}{l}\text { Mainly } \\
\text { skills }\end{array}$ & $\begin{array}{l}\text { National data- } \\
\text { bases }\end{array}$ & $\begin{array}{l}\text { Skills strategy } \\
\text { for managing } \\
\text { national skill } \\
\text { systems } \\
\text { Statistical } \\
\text { analysis }\end{array}$ & $\begin{array}{l}\text { Possible, but } \\
\text { mainly ana- } \\
\text { lyzing at na- } \\
\text { tional, not } \\
\text { skill level }\end{array}$ \\
\hline $\begin{array}{l}\text { CEDEFOP's } \\
\text { European } \\
\text { skills and job } \\
\text { survey [5][6] }\end{array}$ & $\begin{array}{l}\text { Skill gap anal- } \\
\text { ysis }\end{array}$ & $\begin{array}{l}\text { Question- } \\
\text { naires filled } \\
\text { by } 48 \quad 676 \\
\text { adult employ- } \\
\text { ees in the } 28 \\
\text { EU Member } \\
\text { States }\end{array}$ & $\begin{array}{l}\text { Statistical } \\
\text { analysis }\end{array}$ & 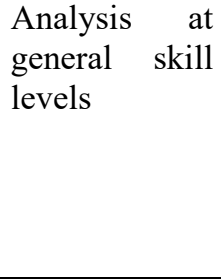 \\
\hline
\end{tabular}

These studies highlighted future competences based on the experts' actual opinions about the future or statistical analyses. The first two studies contained mostly qualitative analyses, diminishing the chance to examine the role of different influencing factors. However, they provide us new insights with defining new skills. The last two studies used quantitative analyses based on past data, so the changes of influencing factors can be examined within these databases. Nevertheless, the current skill categories served as a basis for these analyses.

The goal of this work is to develop a system for revealing the relative importance of different competences in the future. Hence, it exploits the result of the previous studies, 
but it complements them as well. The qualitative studies must be repeated in order to detect the changes in the environment. The quantitative studies have no interest to modify their categories, because trend analysis requires strict meta-data catalogues to discover patterns or correlations along time dimensions. These approaches can complement each other and information system can synthetizing their advantages. It is capable of monitoring current situations, collecting open data as past data, performing forecasts based on them, presenting the results of different business scenarios due to the changeable parameters, so it is dynamically changeable but the other ones are not.

\subsection{Beyond the State of the Art}

These studies use models to collect the experts' current thoughts about the future. They do not capitalize the benefits of information systems which are capable of formalizing experts' thinking processes, opinions to create models, continually detecting the actual situations and mixing these outcomes to get a more precise estimation.

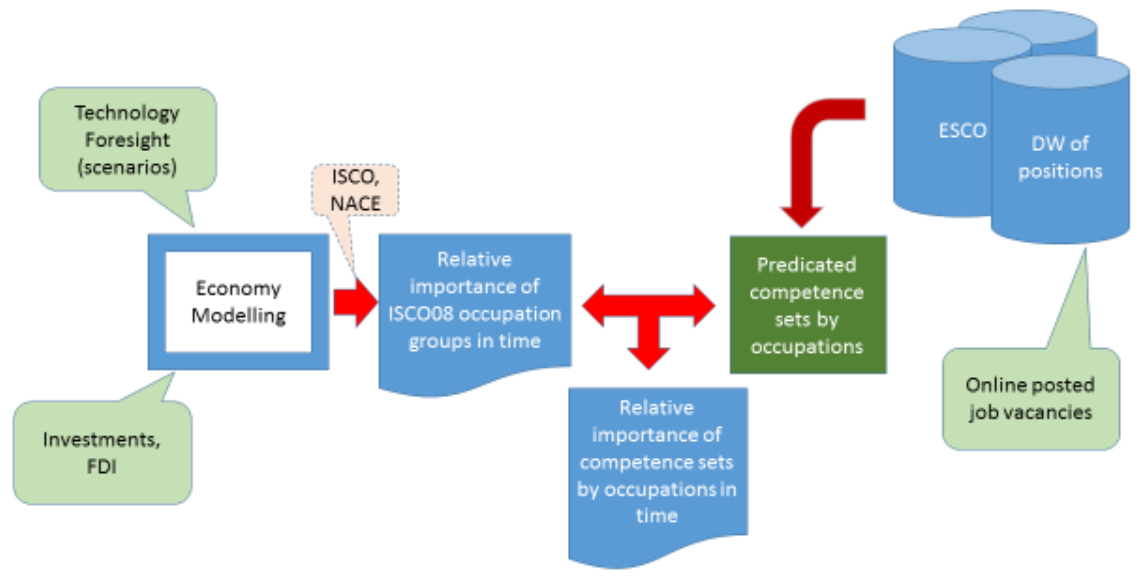

Different factors can influence the relative importance of future competences. Economic factors - like GDP, imports and exports can, sectoral outputs etc. - and technological innovations - like smart systems, blockchain etc. - can influence the labor intensity of different sectors. This takes effect on occupations as well. The relative importance of occupations belonging to a more labor-intensive sector will increase. But competences are required to execute different tasks of these occupations. Therefore, the relative importance of these skills will grow. Input-output model developed by Leontief suits this problem, because it is widely used to model industrial outputs, cross-consumptions and labor intensity. Input data of this model can be downloaded due to the Open Government Data initiative. Sectors categorized by NACE represents the industries in this model. Occupations classified by ISCO-08 are connected to these NACE sectors and their distributions are published as open data. The relative importance of different ISCO-08 groups is determined on this way. 
Unfortunately, the distributions of ISCO-08 subgroups per sector are not available therefore, another source have to be used to estimate them.

The aim of SMART project (2012-1-ES1-LEO05-49395) [7] was to monitor actual competence needs via online posted job vacancies and compare them with the competences acquired during VET studies in the tourism industry. The SMART + project (2016-1-ES01-KA202-025304) [8] as its successor is to provide a comprehensive system for detecting skill gap for students and for institutions as well. Besides a comprehensive skill mismatch report, it provides a report concerned on just some positions. This system is capable of downloading and categorizing job vacancies by position, company, time and regional dimension, and extracting, storing competences required by the position. Another but connected research deals with creating a data warehouse from these datasets in order to monitor and analyze skill mismatches anytime and anywhere. At the end of the development process, monthly data will reside in this data warehouse (DW). ESCO [9] helps to connect the stored positions to occupations and it presents competences per occupation, which can be used to extend the above-mentioned extracted competence sets with new ones. The predicated competence sets per occupation will be calculated within the DW. Their relative importance means that we can state that a competence will be more important than another one, but we cannot state how many times it is. This relative importance will be calculated based on the predicated competence sets per occupation and the aggregated relative importance of the occupations requiring these competences within the ISCO-08. We assumed that the competence can inherit the importance of an occupation, because it is needed to execute a task and if more this kind of position is published then more this kind of task and its competences are required.

Main concepts and areas are clarified in the following sections.

\section{Competence}

One of the objectives of European Union long term strategy (EU2020) is to create the Single European Market (SEM). In the context of SEM, the macro-regional mobility highlights the questions of free movement of manpower. One aspect of the free movement of manpower is the workforce knowledge, skill and attitude - competences in short - compliance from the perspective of the different Member States. Member States are not only geographically different, but differ significantly in terms of work culture. On corporate level, in the context of employees and employers it is a vital interest to get evidence of existing competences of the new employees, or having a timely monitored competence evolution of the staff.

There is a big terminology bonanza in this area. We are talking about competency and competences, knowledge, skill and attitude, autonomy and responsibility, job role, position and occupation, match and mismatch skills, job seekers, free movements of manpower, migrants and refugees, mobility, career development, employability and unemployment, labor market integration and re-integration .... the list is endless.

Competences has many interpretations in the literature and academia, especially in accreditation processes. In this paper, in our understanding competence is a mix of 
knowledge, hard/soft and transversal skills, attitude, autonomy, responsibility. This interpretation is often mentioned as employability skills. On micro level, required competences are linked to the job to be performed. From modelling point of view, jobs emphasized in tasks, and tasks are organized into business processes. Job roles, and their descriptions (in the sense what performers need to know and be able to perform the task) are part of one or more positions, connecting this way process and organizational views together.

While employers, corporates look for competences in connection with positions and connected job roles, on macro level the competences grouped and associated with occupational structure. An occupation is an element of the statistical nomenclature, positions and occupations are strictly linked together by administrative means. The mutual assignment is not without problems: the competence structure mirrors the present and future demand of industry, service sectors, and changes dynamically, however occupational structure is a rather rigid, follows a statistical nomenclature and changes are much less frequent. The occupational structure depends on macro structural variables, educational and training systems.

\section{Stakeholders /interested parties}

Competence matching is a wider issue, than many of us would have thought. Many types of stakeholders are interested in it, from different perspectives.

On supply side, first of all employers, owners and managers of individual firms play the most significant customer roles. In addition, different (traditional and online) manpower services either from recruiting or selection purposes are significant stakeholders, but many professional associations offers also guidelines, conduct surveys in this direction. Finally, education sector, as one of the largest suppliers of graduates must know how effective they are.

On demand side, we must mention graduates, employees with mobility or career exchange motivation, unemployed to be re-integrated, any job seeker, in general.

\section{Supply / demand}

\subsection{Supply}

Available workforce may come from several sources. Academia, education sector is one of the main source, the output of the sector is well planned and it is relatively easy to forecast. From available or potential competences, we must take into consideration other forms of education/training, like informal, non-formal education, on the job-training, continuous education. From motivational point of view, the career exchange is an important driver, resulting extra job seekers with new or changed competences. Another source is the internal or macro-regional mobility, especially within EU, although this is not without any problem (cf. Brexit). We may mention also the re-integration of the unemployed people. Finally, the migration plays important role, which is a more complex problem, than just a manpower issue 


\subsection{Demand}

Demand is also complex. Employers are quite different regarding their expectations, in the first group there are employers who request well-trained workforce whom they can use on the next day with full capacity, while another group of employers demand intelligent, 'smart' people, who are able and know how to learn, while training remain the employers' responsibility. The scale between the two groups is long and colorful. We need to highlight three specific drivers, which influences the demand: replacement due to the mobility, additional workforce due to economic growth and workforce with different competences due to the technological development.

\section{$5 \quad$ I/O Model}

\subsection{Model selection: why input-output model?}

The Leontief model, known as I/O analysis emphasizes the effects of change in the final demands for goods and services on particular industry with respect to its sales and purchases.

"The input-output method is an adaptation of the neoclassical theory of general equilibrium to the empirical study of the quantitative interdependence between interrelated economic activities. It was originally developed to analyze and measure the connections between the various producing and consuming sectors within a national economy... The specific structural characteristics of the system are thus determined by the coefficients of these equations. These coefficients must be determined empirically; in the analysis of the structural characteristics of an entire national economy, they are usually derived from statistical input-output tables" [10]

Leontief gave an extended interpretation to the coefficients the most important among them were the following: the coefficients have a statistical character, therefore they can be estimated; different coefficients based on the estimation statistically are quite stable, hence the model is suitable for different kinds of analyses, like assumption of different economic growth, changes in industry structure, etc.; the analyses may lead to quantitative evaluation of different economic policies, comparison of their indirect effects, accelerator effects or counter effects.

Later in the light of quite different economic theories and also due to the radical changes of global economy, many argued that I/O model has not reflect anymore objectively to the real life of national economy. However, the coefficients - in other word technological matrix - are based on statistical data and still the most reliable although not the only data source for modelling. Adding to the model the capital investments, taking into account the modification effects of export-import activities, the I/O model still gives a good starting point for analysis. On the basis of the model results environmental effects, ecological considerations, the strengthening of third sector will be more understandable and lead to a more complex approach (Stilwell \& Minnitt 2000).

From the perspective of this paper, we must emphasize the biggest advantages of using I/O model that is it can be built on official statistical data. The validity of data ensured by the national and macro-regional statistical data collection systems, and most 
of them is available in 'open data' format. The later mentioned feature means, the experiments; analyses can be reproduced in an automated fashion.

\subsection{Data sources}

\section{Open Data / OGD / GOD}

Central Statistical Office (CSO), Hungary

The data on persons employed in the Hungarian economy, according to NACE Rev. 2 (2008) 1 classification, is published by the Hungarian Central Statistical Office on its website together with other information of the national accounts. The information on persons relating to national account is important mainly for the calculation of the ratio, value added per worker in each industry of the national economy.

\section{Eurostat}

EUROSTAT provides industry-by-industry symmetric input-output tables. Hungarian data in ESA 1995 format was used from their data source. The output matrix is an object as it is structured by industry. This organization presents supply and use tables and symmetric input-output tables that are a fundamental part of the European System of Accounts (ESA 1995).

\section{$O E C D$}

The Organization for Economic Co-operation and Development (OECD) is involved for preparing Inter-Country Input-Output (ICIO) tables which based on different International Standard Industrial Classification of all economic activities (ISIC) revised version. The previous OECD national Input-Output tables present matrices of inter-industrial flows of goods and services (produced domestically and imported in current prices (USD million), for all OECD countries including 28 members of European Union and G20 economies, covering the years 1995 to 2011 based on the ISIC Revision 2.

The latest version of ICIO tables are based on ISIC revision version 3. The better integration with collections of statistics accumulated according to industrial activity such as research and development expenditure, employment, foreign direct investment and energy consumption. The OECD I/OT database is a very useful experiential tool for economic research and structural analysis at the international level as it highlights inter-industrial relationships covering all sectors of the economy.

World Input-Output Database (WIOD)

\footnotetext{
${ }^{1} \mathrm{NACE}$ is the statistical classification of economic activities in the European Community which imposes the job classification uniformly within all the member states of European Union. NACE Rev. 2 reflects the technological developments and structural changes of the economy, enabling the modernization of the community statistics and contributing, through more comparable and relevant data at both community and national level.
} 
The World Input-Output Database (WIOD) is the first public database that contains new information on the nature of international trade and trends and provides the opportunity to analyze the consequences of division for shifting patterns in demand for skills in labor markets. These tables have been put up in a clear conceptual framework on the basis of officially published input-output tables in concurrence with national accounts and international trade statistics. In addition, the WIOD provides data on labor and capital inputs at industry level.

\section{Concluding to demand}

As it was outlined in the previous sections, the I/O model is used to do predictions on the changes of occupational structure, due to the economic growth, changes in productivity and the expected technological developments. In order to get the results, the gross domestic output per sector, used labor force / output unit, distribution of labor force / sector / occupation will be used as variables. With the help of ESCO ontology and database, we conclude to the expected competences / occupation. Difference between the expected and supplied competencies already provides sound basis of portfolio decisions.

\section{Comparison (matching) competences}

\subsection{Requested competences / occupation}

The first problem is how to conclude from the I/O model to the requested skills/competence structure. As we saw in the previous sections, I/O model, the coefficients results output per sectors, labor intensity and quantity per occupations, as they are classified by NACE. The granularity of occupations is very rough. We increase the specificity of occupations combining the occupations with sector. At this point, the ESCO database can be of great help, and with the help of ESCO the requested competences can be better positioned per job roles.

\subsection{Available (provided) competences / occupation - EQF/National QF}

The other - supply - side of competences seems to be easier issue. The EU accepted the European Qualification Framework (EQF)[12], similar frameworks exist elsewhere, too. The EQF is very general, the national qualification frameworks are more detailed and localized, and on institutional level, we can get very precise and concrete competence (often called as learning outcome) lists - at least what institutions claim to provide. For the sake of simplicity less assume, graduates have those competences.

The comparison of supply and demand will undertake by using SMART and SMART+ system ${ }^{2,3}$.

\footnotetext{
2 SMART - Supporting dynamic MAtching for Regional development, 2012-1-ES1-LEO0549395

${ }^{3}$ SMART PLUS 2016-1-ES01-KA202-025304
} 


\subsection{Analysis: 'What if' scenarios}

\section{Time horizon / preference selection}

The next problem is to select the suitable time horizon. The lower limit will be the minimum time, during which any change is becoming 'visible' on the national accounts, become manifest statistically. Theoretically, there is no upper limit, only limitation how far we can see in the future to keep the possible scenarios still realistic. If we consider the 'lead time' of a typical higher education institution, the most appropriate time horizon is between 3-5 years.

\section{The growing economy (Foreign Direct Investment)}

In general, economy may grow due to several reasons, increasing productivity, growing export, growing domestic demand, large volume of international aid (e.g. EU Structural and Cohesion Funds), etc. A special case is the Foreign Direct Investment, the investor is not selling or buying something but creates production sites, jobs, and the economic growth is based both on the direct investment and the additional gross domestic products due to the accelerator effect ${ }^{4}[13]$. I/O model is suitable to reflect both (direct and indirect) effect. In the first scenario we assume, the recently experienced fast development of electric car manufacturing will effect on the volume and structure of FDI. Retail sale of fossil energy is expected decreasing, energy sector as a whole need to be restructured, more investments, and technological development is needed, while the agro-based renewable energy production will decrease.

As a result, the inter-relations of the sectors will change, the overall domestic output will be increased. As one of the consequence, the labor-part of the GDP will change as well, both in terms of quantity and occupation structure, hence the change requests different skill-set and follows the changes in occupational structure (for the sake of simplicity linearity is assumed, which results some bias).

\section{Changing the requested labor force (productivity, unchanged structure)}

In the EU and G20 countries, a sound increase of productivity is monitored [14]. The annual average is around $20 \%$, with very big differences among the countries. The largest improvement happened in Ireland and 135\% productivity index is expected by 2018 $(2010=100)$. From the point of occupational structure and demanded skill set point of view we may model the quantitative changes through the labor coefficients. The question is, in what extent will follow the occupational structure the increasing productivity (the assumption is the less-skilled workers' ratio will decrease).

\section{Changing the requested labor force (technology, different structure)}

The new technological phenomenon, the fast growing ratio of electric cars among the vehicles. Norway e.g. expects electric or hybrid cars make up half of new vehicle registrations in 2017 [15] E-car manufacturing needs significantly less skilled jobs in

\footnotetext{
${ }^{4}$ However in 2016 the FDI fall $7 \%$ according to the OECD data, on a longer term increase is expected [13]
} 
the traditional machinery sectors, although less but better trained and skilled workers in the designer and constructing parts of car manufacturing. These changes will lead to the changes in the occupational structure.

On the other hand, the forecasted technology breakthrough will affect not only the manufacturing sector but significant changes are expected in the energy sector, too. Electric Vehicles (EVs) promise technology for reducing the environmental burden of road transport. Other energy types like renewable energy production provides the largest market swing over time: from 19\% of production in 2010, 32\% is expected in 2020 and will continuously grows up to $50 \%$ by 2050 [16].

Technology plays a vital role for changing labor market trends. Several industry studies in equal extent say that fully autonomous vehicles are to be commercially available before 2020. In 2030, the share of electrified vehicles could range from 10 percent to 50 percent of new-vehicle sales.

As a consequence the technological impact on the demand side of labor market implies structural changes of required competencies. Educational institutes need time to change their educational portfolio due to the lead-time of formal education. A system, which is capable to predict the future occupational structure and conclude to the required competencies, can facilitate decision making processes both in the educational institutes and in the world of labor.

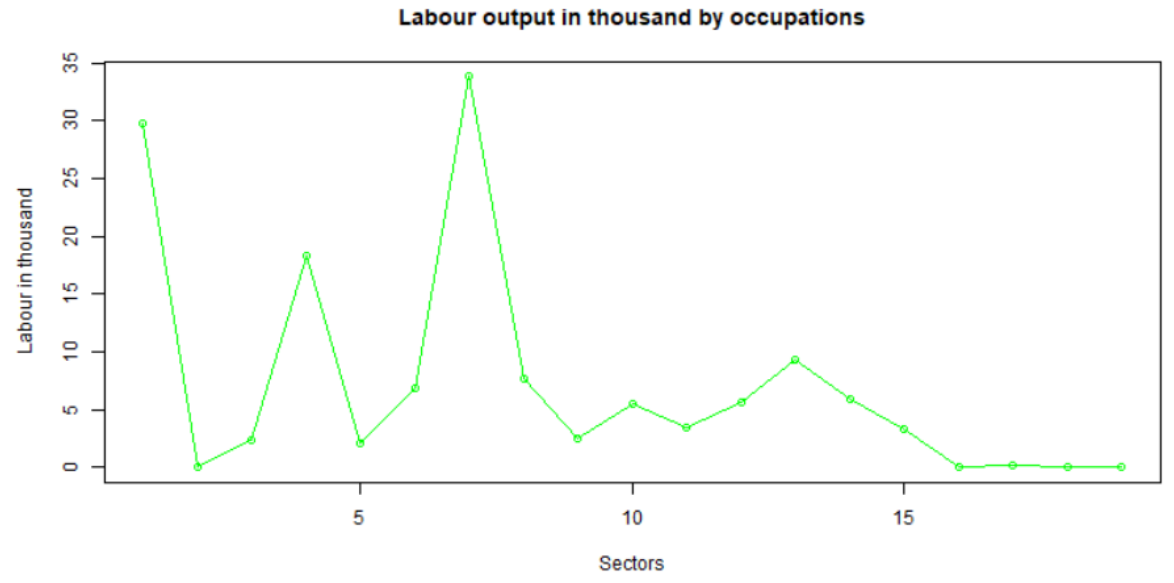

Fig. 1. Number and distribution of managerial position by sectors

A business scenario reflecting the influence of growing number of electric car was used to present the working of this system. Fig. 1. shows the expected changes in terms growth of output, improving productivity and creating new (skilled) jobs will change the localization of the managerial positions. The result is almost double the demand for skilled workers, and the relatve need is bigger in the productive sectors (first economy) than in the second and third. 
Nowadays ESCO collected the main managerial aspect like "plan, organize, coordinate, control and direct the work done by others." Fig.1. presents that managerial jobs and related competences will be important in the future. There are managerial competences specialized in a given sector e.g. monitoring fields and managing agricultural staff by a crop production manager or monitoring technological trends and managing contracts by an ICT production manager and there are general competences related to different managerial job roles [9]. Fig 2. presents how these general competences are distributed among 19 selected occupations . It shows that the "adhere to organisational guidelines" competence is required by seven different managerial occupations.

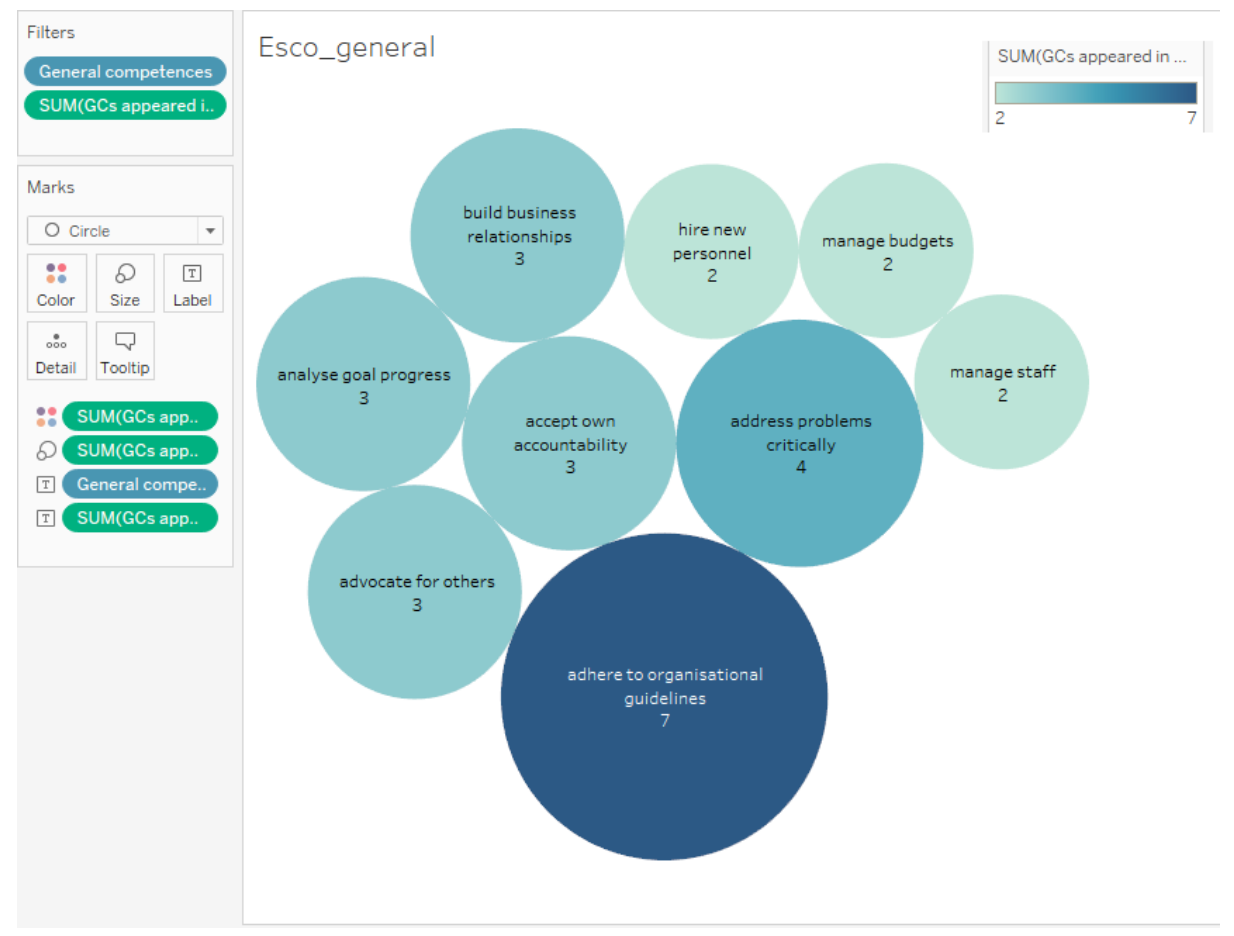

The system presented in this paper is capable of estimating the importance of occupations affected by changes in industrial structures and the importance of specific and general competences belonging to these occupations

The selected most important competences can be compared with the competences provided by a training program via Smart+ system. This gives very clear indication to the education sector how and in which direction develop their portfolio.

To execute deeper analysis along the hierarchy of ISCO occupations, the distributions of these occupations per main group are needed. If publishing governmental data on Internet will be a best practice, it solves this problem. 


\section{Discussion, conclusion}

It is difficult to validate that our prediction is appropriate or not, because different factors are counted in by different research groups. The goal of this paper is not to predict the future. Its goal is to present a conception about developing an information system in order to formalize experts' thoughts via business scenarios by input-output model and check the influence of labor-intensive sectors on related occupations and competences.

The development of this system is ongoing. The concept of Open Government Initiative (OGI) has to be adapted widely in order to get relevant databases from every year in order to make this system capable of monitoring actual open data and modifying results based on them, meaning to make it dynamically adaptive to the variant environment. The distributions of occupations per ISCO-08 main group, per industry, per country are missing. OGI can solve this problem or a data warehouse that can provide statistical analysis based on past data as we plan.

The novelty of this system is to collect input-output and labor market data dynamically from Internet, it these data are available, apply directly input-output model to these data, provide opportunity to test future scenarios about the effects of technological changing on the labor market and determine competence sets for further analysis. It helps to redesign competence sets provided by training programs in the light of business scenarios derived from the business climate of Industry 4.0.

\section{$7 \quad$ Acknowledgement}

cLINK (Centre of excellence for Learning, Innovation, Networking and Knowledge) ERUSMUS MUNDUS Project, Ref: 372242-1-2012-1-UK-ERA MUNDUS-EMA21

\section{References}

1. Home - Smart Specialisation Platform, http://s3platform.jrc.ec.europa.eu/, last accessed 2017/08/28.

2. Hartmann, E.A., Bovenschulte, M.: Skills needs analysis for "Industry 4.0" based on roadmaps for smart systems. In: Using Technology Foresights for Identifying Future Skills Needs. Global Workshop Proceedings. pp. 24-36 (2013).

3. Davies, A. et al.: Future work skills 2020. Institute for the Future for the University of Phoenix Research Center. (2011).

4. OECD: Skill for a Digital World, http://www.oecd.org/els/emp/Skills-for-a-DigitalWorld.pdf, last accessed 2017/08/21.

5. Cedefop's European skills and jobs survey data released!, http://www.cedefop.europa.eu/en/news-and-press/news/cedefops-european-skills-and-jobs-survey-data-released, last accessed 2017/08/21.

6. Briefing note - People, machines, robots and skills, http://www.cedefop.europa.eu/en/publications-and-resources/publications/9121, last accessed 2017/08/21. 
7. Smart-Project, http://www.smart-project.org/, last accessed 2017/08/28

8. Smart Plus Project - Official Website, http://smartplus-project.org/, last accessed 2017/08/28

9. ESCO - European Commission, https://ec.europa.eu/esco/portal/home, /, last accessed 2017/08/28

10. Encyclopedia.com, Input-Output Analysis - Dictionary definition of Input-Output Analysis | Encyclopedia.com: FREE online dictionary, http://www.encyclopedia.com/social-sciences/applied-and-social-sciences-magazines/input-output-analysis $/$, last accessed 2017/08/02

11. Stilwell, L., Minnitt, R.: Input-output analysis: its potential application to the mining industry. The Journal of The South African Institute of Mining and Metalurgy. 455-460 (2000)

12. European qualifications framework (EQF), http://www.cedefop.europa.eu/hu/events-andprojects/projects/european-qualifications-framework-eqf/, last accessed 2017/08/02

13. Foreign Direct Investment Statistics: Data, Analysis and Forecasts - OECD, http://www.oecd.org/corporate/mne/statistics.htm/, last accessed 2017/08/17

14. Level of GDP per capita and productivity, http://stats.oecd.org/Index.aspx?DataSetCode=PDB_LV, last accessed 2017/08/18

15. Half of all new cars in Norway are electric or hybrid | World Economic Forum, https://www.weforum.org/agenda/2017/03/norway-is-leading-the-charge-towards-electricvehicles-and-just-hit-another-milestone-along-the-way-d69a8170-cbdc-4d8a-95cdf9bdf3c8e3ae/, last accessed 2017/08/18

16. van Essen, H., Kaupman, B.: Impacts of electric vehicles: summary report. (2011).

17. Lu, Y..: Industry 4.0: A Survey on Technologies, Applications and Open Research Issues. In: Journal of Industrial Information Integration 6. 1-10. https://doi.org/10.1016/j.jii.2017.04.005. (2017) 